\title{
ON REAL AND APPARENT EXTERNAL BLEEDING IN THE NEWBORN
}

\author{
BY
}

\author{
W. S. CRAIG \\ From the Department of Paediatrics and Child Health, the University of Leeds
}

(RECEIVED FOR PUBLICATION APRIL 28, 1961)

Newborn infants are especially liable to haemorrhage. External bleeding is more frequent and associated with a more favourable prognosis than internal haemorrhage. Visible evidence of bleeding may appear in the superficial tissues, or in the form of haematemesis, melaena, haematuria or haemoptysis. In whatever situation, visible bleeding may be due to one or more causes. Thus blood in vomitus or expelled per rectum may be evidence of postnatal, foetal or maternal haemorrhage; and postnatal haemorrhage giving rise to haematemesis or melaena may originate in the gastro-intestinal tract or in the bucco-naso-pharynx. This paper presents a clinical study of the circumstances associated with visible bleeding seen in 345 newborn babies over the period January 1, 1949 to December $31,1960$.

\section{Material and Methods}

Of the 345 infants, 253 were born in a maternity teaching hospital, 83 in their own homes and nine in nursing homes. There were 169 males and 176 females. The estimated gestation period of 102 babies was less than 38 weeks, and the birth weight of 78 was $5 \frac{1}{2} \mathrm{lb}$. or less. Delivery was normal in 263 , instrumental in 51 and by caesarean section in 31 instances. The presentation was vertex in 302 and breech in 34 cases; the face or shoulders presented in nine cases.

All babies in the series were under the personal supervision of the writer. Those born in hospital were observed from the time of birth, and those born elsewhere from the time of admission to hospital on account of external bleeding. Clinical observations representing the agreed views of the senior nursing and medical staff were recorded daily or at shorter intervals. Bleeding in all the babies of the series was recognized in the course of naked eye examination, and clinical observations were confirmed in the case of melaena and haematemesis by use of the benzidine test and in the case of haematuria by use of the guaiac test. The presence of large numbers of red blood cells on microscopical examination of bright red expectorated material was accepted as confirmation of haemoptysis.

The extent to which use was made of laboratory investigations was determined by the clinical characteristics of the bleeding and by the laboratory tests available at the time. The haemoglobin percentage and red blood cell counts were determined in the majority of infants. A haemoglobin of $70 \%$ $(11 \cdot 3 \mathrm{~g}$. per $100 \mathrm{ml}$.) or less on the ninth or tenth day of life was accepted as evidence of anaemia. Prothrombin time estimations, using Quick's onestage method, were carried out on 133 babies, using venous blood. A prothrombin time $75 \%$ or more in excess of that of a control adult plasma was accepted as evidence of a coagulation defect. In differentiating foetal from maternal blood use was made of alkali denaturation tests in the study of 43 cases; in nine of these confirmation was obtained by phase contrast microscopy.

\section{Clinical Findings}

Anatomical Site of the Haemorrhage. In Table 1 the various forms of bleeding are grouped according to their anatomical situation.

Miscellaneous Group (7). Haemorrhage in the

TABLE 1

INCIDENCE OF DIFFERENT TYPES OF BLEEDING IN 345 INFANTS

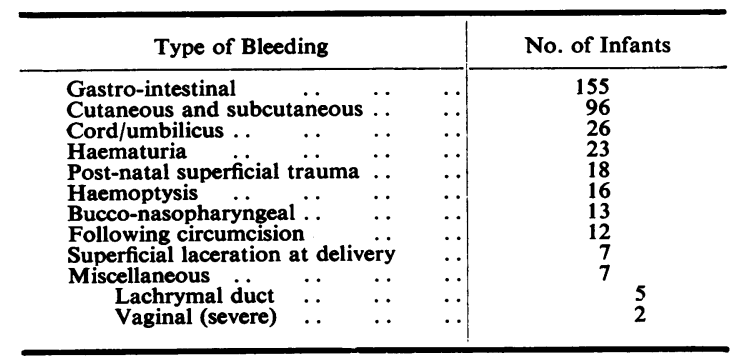

Bleeding of more than one type occurred in 24 infants. 
two babies with bleeding from the vagina was copious, commenced on the second day of life, persisted for 48 hours and was associated with bleeding from the cord and into the skin, and with a prolonged prothrombin time. Bleeding in the neighbourhood of the lachrymal duct in five infants was minimal in amount and consisted of a serosanguineous discharge appearing towards the end of the first week of life in two, and of a small haematoma occluding the lachrymal duct and noticed within 24 hours of birth in three baties. The sero-sanguineous discharges gave Staphylococcus aureus on culture, responded to local treatment and were the result of ascending nasal infection. Occlusion of the lachrymal duct by a haematoma contributed to unilateral excess lachrymation for a period of seven to 10 days pending the gradual spontaneous disappearance of the haematoma. There was no evidence of trauma, infection or bleeding elsewhere in these three cases.

Superficial Laceration at Delivery (7). Bleeding was accounted for by accidental incision of the scalp behind an ear in the course of delivery by caesarean section in three babies; and by infected lacerations of the scalp following the application of Willet's forceps in two infants. In a sixth infant the posterior aspect of the neck was deeply cut at the time of incision of the mother's undilated uterine cervix during delivery by the breech. The seventh case consisted of profuse bleeding from laceration of the frenulum of the upper lip as a direct result of the application of forceps. There was extensive bruising of the lip.

After Circumcision (12). The 12 infants were operated on on the seventh or eighth day of life. In five bleeding was arterial and ceased with ligation. Haemorrhage in a sixth infant was due to secondary infection with Esch. coli. There were two infants in whom an increased prothrombin time was associated with haemorrhage in other sites, and one in whom an increased prothrombin time was the only finding. Bleeding was unaccounted for in three babies, but ceased after the application of a local adrenaline dressing. The one instance of haemorrhage attributable to infection commenced 36 hours after operation, persisted for 48 hours but was not copious. In all the other 11 infants bleeding started suddenly within six to 17 hours of circumcision and when of arterial origin rapidly assumed considerable proportions. Two of the babies with arterial bleeding needed a transfusion.

Bucco-nasopharyngeal (13). Bleeding was from the nose in eight, the palate in three, and the pharynx in two babies. Epistaxis was moderately severe in five infants in all of whom the prothrombin time was prolonged, but in only three of whom was there visible haemorrhage elsewhere. In the remaining cases bleeding took the form of blood-stained mucoid nasal discharge (present before nasal catheterization) in two infants with choanal stenosis and in one premature baby with severe congestive rhinorrhoea. The rhinorrhoea in this last infant was attributable to irritation by regurgitated gastric contents.

Palatal bleeding originated from a small ulcerative granulomatous lesion involving the soft palate in one infant, and in two other babies from minute, clearly defined ulcers with hyperaemic bases situated immediately adjacent to the median raphe of the mucous membrane lining the hard palate. The lesions in these three babies were noticed within 36 hours of birth, disappeared spontaneously within five to seven days and did not resemble Bednar's aphthae as described in the literature. There was no evidence of monilial, syphilitic or other local or general infection. Bleeding consisted of a persistent small loss sufficient to stain the salivary secretion. Abrasion of the mucous membrane by a mucus catheter accounted for bleeding from the pharynx in two babies. Haemorrhage was minimal and of short duration and caused less distress than the associated 'rasping', mildly stridorous spasmodic cough.

Haemoptysis (16). The details of babies with haemoptysis are summarized in Table 2. Copious haemoptysis was a terminal event in three babies with cyanotic congenital heart disease; three with gross developmental anomalies affecting both kidneys; two with signs of classical cold injury; and one with congenital thrombocytopenic purpura. Circulatory failure preceded haemoptysis in all nine of these cases. Haemoptysis occurred in two babies who showed evidence of severe intracranial irritation during life and who after death on the fourth and fifth days of life respectively were found at autopsy

TABLE 2

HAEMOPTYSIS ACCORDING TO CAUSE (16 INFANTS)

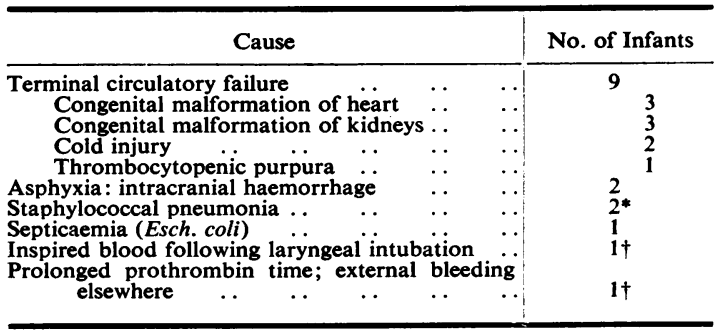

* One survived.

$\dagger$ Survived. 
to have extensive intracranial haemorrhage. In neither infant was the prothrombin time prolonged on the third day and in each the blood in the vomitus was foetal in character. Blood-stained mucus coughed up into the bucco-pharynx was a feature of two babies (of whom one survived) with staphylococcal pneumonia and of one infant with fatal coliform septicaemia. The bleeding in these three babies persisted for a number of days. Inhalation of blood, mild haemoptysis and stridorous cough followed trauma to the larynx at the time of resuscitative endotracheal intubation of one severely asphyxiated baby. This infant recovered, as also did one other in whom mild haemoptysis commencing on the third day of life and persisting for 24 hours occurred in the presence of simultaneous bleeding in other sites and of a prolonged prothrombin time.

Thirteen infants died.

Superficial Trauma of Post-natal Origin (18). Unavoidable trauma to superficially situated anomalous tissues accounted for bleeding in 11 babies. This applied to the gentle oozing of blood from the exposed surfaces of extensive meningomyeloceles (six) and more profuse bleeding from abrasion of large or multiple haemangiomata so situated that they could not be constantly and effectively protected from friction or pressure (three). Two infants had small circumscribed ulcer-like congenital defects of the scalp with vascular pericranial bases from which gentle oozing of blood took place over a period of 36 hours.

In another baby of not more than 30 weeks gestation, slight bleeding occurred from the base of a trophic ulcer which developed over the right parietal region in the third week of life. Haemorrhage from the lactiferous ducts in the two babies in whom it was noted was the direct result of what can only be described as ill-considered crude attempts at manual expression of the secretion from physiologically engorged breasts. Clinical evidence of secondary infection appeared within 48 hours. Deep, extensive excoriation of the perianal tissues following the persistent passage of frequent abnormal motions in two babies inadequately attended to at home was associated with slight but prolonged oozing of blood from the exposed inflamed surfaces. In another infant infection of an anal fissure was complicated by the development of a peri-anal abscess, the purulent discharge from which was heavily blood-stained and gave a mixed culture of Esch. coli and Staphylococcus aureus. Bleeding in the eighteenth case in the group was due to superficial erosion of a large teratoma originating in the inner canthus of one eye.
TABLE 3

HAEMATURIA ACCORDING TO CAUSE (23 INFANTS)

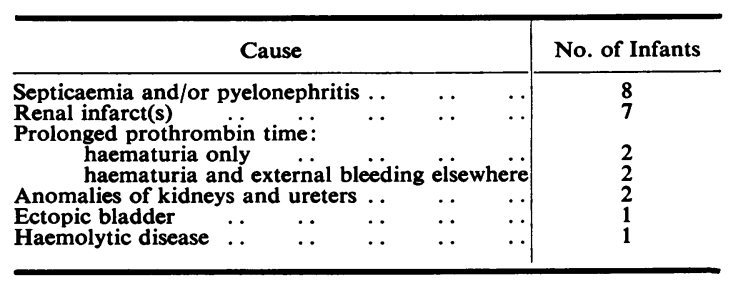

The six babies with meningomyelocele and the one with teratoma died.

Haematuria (23). (Table 3.) In eight babies the haematuria was attributable to pyelonephritis, the infection being due to Esch. coli in five, Staphylococcus aureus in two, and undetermined in one. The renal condition was part of a generalized septicaemia in three of the cases due to Esch. coli. One of these three infants died. Hydronephrosis and hydroureter were features of two of the cases in which there was no evidence of septicaemia.

Renal infarction accounted for the haematuria in seven babies. In four instances haematuria synchronized with readily palpable clinical enlargement of one kidney. In each baby renal infarction occurred as a terminal event in the presence of a failing circulation. Four of the infants died from congenital heart disease, and death was contributed to by a combination of cardiac and renal anomalies in two other babies. The seventh baby with renal infarction died as a result of progressive emaciation in the presence of a meningomyelocele and rapidly increasing hydrocephalus. Haematuria was present in two infants with anomalies of the ureters and renal pelves, which were radiographically demonstrated but apparently uninfected. Increased prothrombin time was a feature in four babies, in two of whom petechiae developed on the fourth day of life, together with melaena in one. The two remaining infants were examples of other forms of bleeding. In one, a rhesus baby, haematuria and cutaneous haemorrhages appeared within two hours of birth and before replacement transfusion; and in the other, oozing of blood from the exposed mucosa of an ectopic bladder persisted for a number of weeks after delivery.

Cord/Umbilicus (26). (Table 4.) Bleeding is best considered according as it occurred within a few hours of birth, some days after birth or with commencing separation of the cord. There were 11 instances of haemorrhage first detected within four to 12 hours of birth. Ligatures had been too loosely (six) or too tightly (two) applied in eight 
TABLE 4

BLEEDING FROM CORD/UMBILICUS ACCORDING TO CAUSE (26 INFANTS)

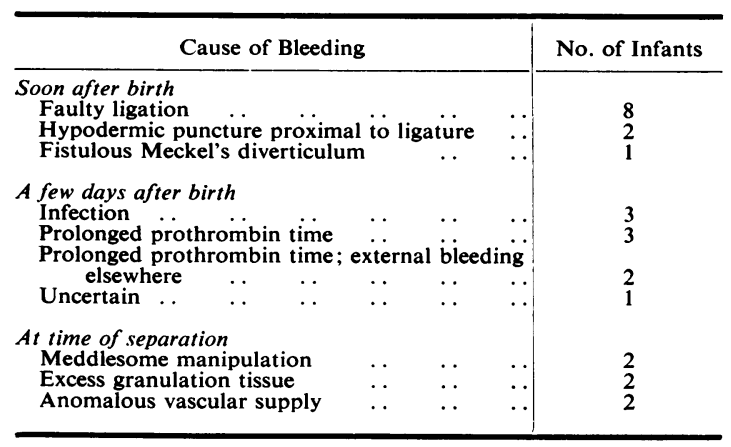

babies: in two infants bleeding took place from the puncture site of resuscitative hypodermic injections given before ligation and proximal to the ligature level: and in the eleventh child external bleeding was the first indication of a fistulous Meckel's diverticulum.

Bleeding commencing three to five days after birth was associated with a prolonged prothrombin time in five and with secondary staphylococcal infection in three babies. There was bleeding in other sites in two of the infants with prolonged prothrombin time, and one of the examples of omphalitis occurred in a baby who recovered from severe cold injury. Haemorrhage on the fourth day of life in one baby was unexplained. Bleeding at a later period was attributable to meddlesome manual attempts to accelerate separation of the cord in two infants. Natural separation of the cord was complicated by haemorrhage in four babies, and was due to excessive amounts of proliferative granulation tissue at the base of the cord in two and to an anomalous arterial supply of the cord in the other two infants. The haemorrhage in the two last-mentioned cases was of sufficient severity to threaten life and necessitated surgical intervention.

Although there were no deaths, exsanguination needing immediate blood transfusion developed with dramatic suddenness in two infants in whom bleeding was due to faulty ligation.

Cutaneous and Subcutuneous (96). The evidence of haemorrhage consisted of numerous petechiae, extensive ecchymoses and contusions, separately or in combination. Instances of cephalhaematoma have not been included, as they were recorded as a routine only during the last year of the study. In that year, during which there were 1954 live births,
33 babies had cephalhaematomata of a size stimulating comment and 30 other babies had subconjunctival haemorrhages.

Numerous petechiae were the only finding in 17 babies of whom two were small premature and two large postmature infants. Delivery of one of the premature infants was by the breech. Of the 17 babies, three were asphyxiated at birth and two died as a result of massive suprarenal haemorrhage. The time of appearance of the petechiae varied. In nine infants it occurred within 24 hours of birth. These nine babies included five with haemolytic disease and the petechiae were present before replacement transfusion. The remaining eight babies with petechiae were examples of inoperable congenital atresia of the bile ducts (three), septicaemia (three), leukaemia (one) and thrombocytopenic purpura (one), and in them cutaneous haemorrhages first appeared in the second week of life or later.

Ecchymoses in the absence of other bleeding tendencies were present in 26 babies. In the majority the ecchymoses were detected at birth or within 24 hours of birth, but exceptionally they first appeared on the second or third day of life. Known local pressure, not invariably of abnormal degree, explained the bleeding in 14 of the babies, but in the remainder there was no convincing explanation. Of the 26 babies 17 were born to mothers with diabetes mellitus and all were premature; and of the remaining nine, four infants were delivered instrumentally after a prolonged labour, and two others were asphyxiated at birth.

Large contusions other than cephalhaematoma were a feature of 18 babies at or shortly after birth. In five cases the contusions merited the description haematoma. The presence of contusions was explained in every case by obstetrical complications. A breech presentation explained severe bruising of the external genitalia and/or perineum in seven babies. Similarly, the presenting structures were the site of contusions in five babies who presented either by the face or brow. Difficulty in delivering a limb accounted for extensive bruising of an arm in one infant and of a thigh in another. There was one example of bruising in the posterior thoracolumbar region due to difficulty in delivering the trunk because of a moderate degree of disproportion. In three babies extensive contusions involving the face coincided with the line of application of forceps blades. Of these three infants, two were delivered by the breech and one by the head.

The group of cutaneous and subcutaneous bleeding includes 35 infants exemplifying the condition sometimes referred to as traumatic cyanosis. From 
the time of birth, or within one or two hours of birth, the head, face and neck were deeply cyanosed. The anatomical distribution of the cyanosis was characteristic and the line of demarcation between proximal cyanosed and distal healthily coloured tissues was clearly defined. The lips and buccal mucous membranes were not involved in the cyanosis. Numerous petechiae were irregularly but profusely distributed throughout the cyanosed surfaces of the face and scalp.

Of the 35 babies the birth weight of six ranged from $2 \mathrm{lb} .10 \mathrm{oz}$. to $5 \mathrm{lb}$. $3 \mathrm{oz}$., and of 29 from $5 \mathrm{lb} .14 \mathrm{oz}$. to $10 \mathrm{lb}$. Presentation was by the head, face and brow in 31, two and two cases respectively. Delivery of six infants was precipitate, being complete before arrival of the accoucheur in two; and labour was notably prolonged in the case of three infants. There were two instances each of rapid delivery of the head, slow delivery of the body, and of severe local pressure exerted by an umbilical cord tightly coiled round the neck.

The obstetrical histories of a number of the mothers were unusual. There were seven cases of pre-eclampsia with hypertension. Two mothers had severe mitral disease; one was a case of active pulmonary tuberculosis; another had an acute urinary infection; and yet another had viral pneumonia immediately before the onset of labour.

In this group of 35 infants there was a history of maternal antenatal ill health and/or an unusual feature in connexion with the labour or delivery in the case of no fewer than thirty. Severe postnatal asphyxia was present in 11 babies and convulsions occurred in two. Bradycardia during the first 48 hours of life was a feature of 10 of the infants, being associated with hypothermia in four. All 35 babies survived the first two weeks of life.

Cutaneous or subcutaneous bleeding was associated with haemorrhage in other situations in 22 babies. The prothrombin time was estimated in 15 of these infants and found to be prolonged in each case.

Gastro-intestinal (155). Loss of blood from the alimentary tract occurred in 155 babies. The clinical evidence of bleeding was melaena in 45, haematemesis in 36 and both melaena and haematemesis in 57 infants. There were 17 other babies in whom external bleeding in other situations was present in addition to melaena and/or haematemesis.

Table 5 analyses the clinical evidence of gastrointestinal bleeding according to aetiology. Diagnosis in the two cases of gastro-duodenal ulcers was confirmed by autopsy findings, and in the two cases of hiatus hernia by observations during screening after oral barium. Haematemesis in the infants
TABLE 5

GASTRO-INTESTINAL ACCORDING TO CAUSE (155 INFANTS)

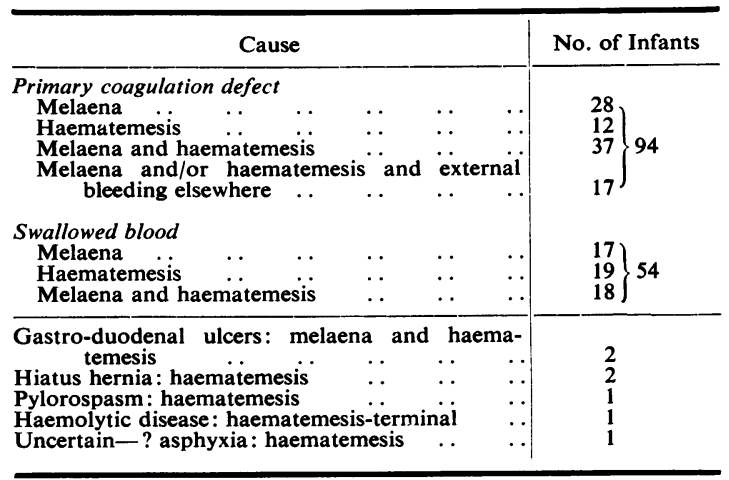

with gastro-duodenal ulcers commenced on the first day of life, was copious and recurred at irregular intervals in the form of dark blood welling up in copious amounts. The appearance of melaena followed that of haematemesis in 12 hours in one baby and 30 hours in the other. In the infant with pylorospasm, diagnosis was based upon the presence of forceful vomiting, large amounts of mucus in the vomitus, a readily palpable contractile thickening of the pylorus and the rapid response to gastric lavage. The bleeding consisted of profuse streaking of the vomitus at the time when vomiting was most forceful, and was considered to be derived from gastric mucosa abnormally congested as a result of the vomiting. This case contrasted with 14 other infants in the total group of 155 (but not included in this section) in whom pylorospasm complicated copious haematemesis and was regarded as evidence of reflex response to the presence of a large amount of blood in the stomach.

Separation of the other examples of gastrointestinal bleeding into the two groups of primary gastro-intestinal haemorrhage due to a coagulation defect and apparent haemorrhage secondary to the swallowing of maternal blood necessitated an analysis of the detailed recorded obstetrical, paediatric and laboratory findings.

A firm diagnosis of primary alimentary haemorrhage was made when blood lost was of foetal and not maternal type, and when there was significant prolongation of the prothrombin time. The otherwise unexplained presence of bleeding in other sites and the subsequent early appearance of a normocytic anaemia was accepted as corroborative evidence. Absence of any history of swallowed blood or blood-stained liquor and delay in the commencement of bleeding until the second day of life or after, provided further evidence in favour 
of a diagnosis of primary haemorrhage. The haemorrhage was considered to be primary in origin in 94 babies.

Of the 94 infants $54(57 \%)$ were born in hospital, $36(38 \%)$ in their own homes and four $(5 \%)$ in nursing homes; and $20(21 \%)$ had a birth weight of $5 \frac{1}{2} \mathrm{lb}$. or less. Delivery was normal in $86(91 \%)$, instrumental in seven $(8 \%)$ and by caesarean section in one $(1 \%)$; 90 infants $(96 \%)$ were head and four (4\%) breech presentations. There was one isolated example of ante-partum haemorrhage; and foetal distress or postnatal asphyxia or both were features of $13(14 \%)$ deliveries. The forms of external bleeding in these 94 babies are given in Table 5 . Bleeding was detected within 24 hours of birth in $17(18 \%)$ of the 94 babies. Thirty-five $(37 \%)$ were males and $59(63 \%)$ females. Haemorrhage in other sites was a feature of 17 cases. There were two deaths in the 94 babies, the immediate cause being massive suprarenal haemorrhage in one and intracranial haemorrhage in the other.

Observations favouring a reasonably confident diagnosis of swallowed maternal blood included the suspected or observed swallowing of blood during or soon after delivery, the presence of blood-stained liquor amnii, a history of antepartum haemorrhage and/or delivery by caesarean section, no significant prolongation of the prothrombin time and determination of the lost blood as being of maternal type. Unexplained subsequent anaemia was unusual. Haematemesis when it is the only sign is more likely to be due to swallowed blood than primary bleeding, and this applies particularly to haematemesis which starts within 24 hours of birth.

In only two of the 54 babies regarded as having swallowed blood was the source of the blood not determined (Table 6). Fissures of the mother's nipples accounted for haematemesis in six breast-fed infants. In another baby, blood in the mother's milk was later found to be due to a carcinoma of

TABLE 6

EXTERNAL BLEEDING IN THE NEWBORN : CIRCUMSTANCES CONTRIBUTING TO SWALLOWING OF BLOOD

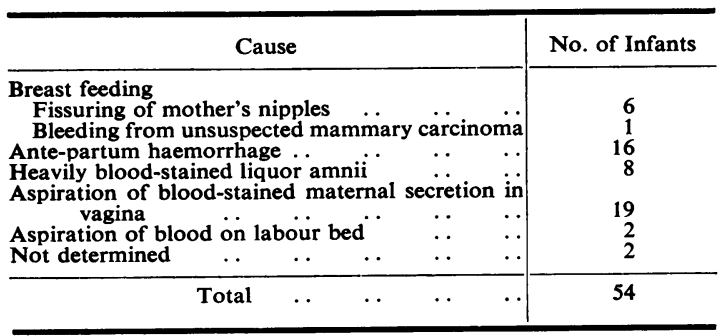

the breast. Antepartum haemorrhage was a feature of the delivery of 16 infants. The liquor amnii was noted as being blood-stained at the delivery of eight other babies. Five of these babies were delivered by caesarean section. Nineteen infants were observed to gasp and swallow blood-stained maternal secretions in the vagina before delivery of the head. Of these 19 babies five were delivered by the breech. There were in addition two prolonged labours, two precipitate deliveries and three instrumental deliveries. The cord was severed on account of shortness during the delivery of two infants. Possible sources of maternal bleeding included an episiotomy incision (three), lacerated cervix (two) and perineal tears (three). Among seven babies born at home, three were born before arrival of the accoucheur, one was delivered by the breech and birth of another was precipitate. Investigation into the circumstances of the delivery of the remaining two justified the assumption that the baby had probably inspired blood before being removed from the mother's labour bed.

Of the 54 infants, $35(65 \%)$ were born in hospital and $19(35 \%)$ in their own homes, and $14(26 \%)$ had a birth weight of $5 \frac{1}{2} \mathrm{lb}$. or less. Delivery was normal in $31(58 \%)$, instrumental in $11(20 \%)$ and operative in $12(21 \%)$. Forty-nine $(91 \%)$ babies presented by the head and four $(7 \%)$ by the breech. There was one example of transverse presentation. Delivery was preceded by antepartum haemorrhage in $14(22 \%)$. Foetal distress or post-natal asphyxia or both were features in the birth of $35(65 \%)$ of the babies. Twenty-six $(48 \%)$ were males and $28(52 \%)$ females. The forms of external bleeding in the 54 infants are given in Table 5. Bleeding was detected in $44(81 \%)$ of the infants within 24 hours of birth. In no infant with haematemesis and/or melaena due to swallowed blood was there external bleeding in other sites. There was one death due to intracranial haemorrhage.

There was considerable variation in the time separating the appearance of swallowed blood as haematemesis and melaena in the same infant. This applied both to cases of primary haemorrhage and swallowed blood. The interval ranged from as little as two to as much as 48 hours. Delay in the appearance of melaena was most common in small premature infants. In them an odour of stale blood was sometimes detectable in advance of the appearance of blood in the motions; and in a limited number delayed or ineffective evacuation of blood from the intestine gave rise to abdominal discomfort, sometimes, but not invariably, associated with distension. 
The Aetiological Background. Considering the various manifestations of bleeding in relation to contributory factors, haematemesis and/or melaena were explained by swallowed maternal blood in 54 cases.

Trauma in a variety of forms accounted for the bleeding in 42 babies, and at a conservative estimate contributed to bleeding in not fewer than 56 other infants. The application of forceps, abnormal presentations and abnormal uterine contraction were the cause of lacerations, severe contusions or haematomata in 24 infants: and there were four instances of accidental incision of the scalp or neck in the course of delivery. Haemorrhage was directly attributable to circumcision in five, and to traumatic procedures involving the cord in four infants. Limited bleeding followed the extraction of mucus in two babies and endotracheal intubation of another. Epistaxis complicated the violent spontaneous expulsion of a large tenacious plug of mucus from the naris of one baby, and a trophic or pressure ulcer of the scalp was the site of bleeding in one small premature infant. Trauma was only one of several factors contributing to traumatic cyanosis, occurring in circumstances which favoured local compression during delivery of the trunk, difficulty in delivering the shoulders and constriction of the neck by the cord.

Infection accounted for haemorrhage in 20 babies. The bleeding took place from the site of circumcision (one), the cord (three), the lachrymal duct (two), and the anus (one). Haemoptysis complicated staphylococcal pneumonia (two), haematuria was present in acute pyelonephritis (eight), and extensive petechial eruptions were a feature of septicaemia (three).

A variety of developmental anomalies contributed directly or indirectly to bleeding in one form or another in 30 infants. Terminal haemoptysis occurred in the presence of fatal congenital disease of the heart (three) and of the kidneys (three); and haematuria resulted from renal infarction in the presence of failing circulation due to congenital disease of the heart (seven). Slight haematemesis was a feature in two babies with hiatus hernia and slight epistaxis in two with choanal stenosis. Oozing of blood took place from a fistulous Meckel's diverticulum (one) and from the traumatized exposed surfaces of extensive meningomyeloceles (six) and multiple large haemangiomata (three). Petechial eruptions developed as delayed manifestations in three infants with inoperable atresia of the bile ducts, complicated by cirrhosis and obstructive jaundice.

Bleeding in a further 106 babies was considered to be due to a disturbed coagulation mechanism, in the absence of other discernible causes. The sites in which haemorrhage took place were gastrointestinal (94), cutaneous and subcutaneous (22), the umbilical cord (five), the nasal passages (five), the renal tract (four), the vagina (two), and the respiratory tract (one). In addition, bleeding which followed the circumcision of three infants was thought to be due to the same cause. The two infants with vaginal haemorrhage represented the only two examples of severe bleeding from the vagina seen during the 11 years of the survey. Minimal physiological menstrual loss was a less frequent finding than expected and detailed observations conducted over a 12-month period demonstrated that it occurred in approximately $6 \%$ of liveborn female infants. In 24 of the 106 babies, external bleeding occurred more or less simultaneously in more than one situation (Table 7). Determination of a defective coagulation mechanism was based on prolongation of the prothrombin time in 77 of the 106 babies.

The age at onset of bleeding ranged from birth to 9 days, but was between 2 and 4 days in the case of 99 infants. Among the exceptions was one baby in whom bleeding from the cord commenced within 30 minutes of birth and persisted for four days; a second baby in whom melaena was present at the age of 10 hours; and two other infants in whom gastro-intestinal haemorrhage continued for several days after starting on the seventh and ninth day of life respectively. Another case of special interest was a baby in whom severe melaena ceased two days after commencement on the fourth day of life, only to recur on the thirteenth day and persist for 48 hours. Clotting and prothrombin times were prolonged in all four infants.

Prematurity was not a predominant feature of the group of babies with intrinsic gastro-intestinal haemorrhage. Of the 94 infants only $23 \%$ were of birth weight $5 \frac{1}{2} \mathrm{lb}$. or under, and $21 \%$ were

TABLE 7

DISTURBED COAGULATION MECHANISM : INFANTS IN WHOM SIMULTANEOUS BLEEDING OCCURRED IN MORE THAN ONE SITUATION (24)

\begin{tabular}{|c|c|c|c|c|c|}
\hline \multicolumn{5}{|c|}{ Sites of External Bleeding } & \multirow[b]{2}{*}{$\begin{array}{c}\text { No. of Babies } \\
12 \\
2 \\
1 \\
2 \\
2 \\
2 \\
1 \\
1 \\
1\end{array}$} \\
\hline $\begin{array}{l}\text { Gastro-intestinal : cutaneo } \\
\text { Gastro-intestinal : cutaneo } \\
\text { Gastro-intestinal: cutaneo } \\
\text { Gastro-intestinal: cord } \\
\text { Cutaneous: vagina: cord } \\
\text { Cutaneous: circumcision } \\
\text { Cutaneous: epistaxis } \\
\text { Cutaneous: cord } \\
\text { Cutaneous: haematuria* }\end{array}$ & $\begin{array}{l}\text { us } \\
\text { us: } \\
\ldots \\
\ldots \\
\ldots \\
\ldots \\
\ldots\end{array}$ & $\begin{array}{c}\text { taxi } \\
\text { matu } \\
\ldots \\
\ldots \\
\cdots \\
\cdots \\
\cdots\end{array}$ & $\begin{array}{l}\cdots \\
\cdots \\
\cdots \\
\cdots \\
\cdots \\
\cdots\end{array}$ & $\begin{array}{l}\cdots \\
\cdots \\
\cdots \\
\cdots \\
\cdots \\
\cdots \\
\cdots\end{array}$ & \\
\hline
\end{tabular}

* Subsequently died: massive suprarenal haemorrhage. 
TABLE 8

HAEMATEMESIS AND/OR MELAENA IN THE NEWBORN: MONTH OF OCCURRENCE

\begin{tabular}{|c|c|c|c|}
\hline \multirow{2}{*}{ Month } & & \multicolumn{2}{|c|}{ Percentage of Infants With } \\
\hline & & $\begin{array}{l}\text { Coagulation } \\
\text { Defect }(94)\end{array}$ & $\begin{array}{c}\text { Swallowed Maternal } \\
\text { Blood (54) }\end{array}$ \\
\hline 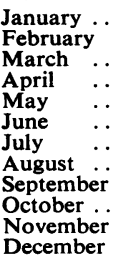 & $\begin{array}{l}\ldots \\
\cdots \\
\cdots \\
\cdots \\
\cdots \\
\cdots \\
\cdots \\
\cdots \\
\cdots\end{array}$ & $\begin{array}{r}11 \\
15 \\
11 \\
5 \\
10 \\
6 \\
8 \\
3 \\
4 \\
9 \\
4 \\
14\end{array}$ & $\begin{array}{r}9 \\
9 \\
11 \\
6 \\
8 \\
11 \\
9 \\
4 \\
9 \\
6 \\
9 \\
9\end{array}$ \\
\hline
\end{tabular}

TABLE 9

FORM OF EXTERNAL BLEEDING IN RELATION TO CAUSE OF DEATH (52)

\begin{tabular}{|c|c|c|}
\hline $\begin{array}{l}\text { No. of } \\
\text { Babies }\end{array}$ & $\begin{array}{l}\text { Major Contributory Cause(s) } \\
\text { of Death }\end{array}$ & $\begin{array}{c}\text { Form(s) of External } \\
\text { Bleeding }\end{array}$ \\
\hline 11 & Congenital heart & $\begin{array}{l}\text { Cutaneous (4) } \\
\text { Haematuria (4) } \\
\text { Haemoptysis (3) }\end{array}$ \\
\hline 6 & $\begin{array}{l}\text { Meningomyelocele : circulatory } \\
\text { failure }\end{array}$ & $\begin{array}{l}\text { Cutaneous (5) } \\
\text { Haematuria (1) }\end{array}$ \\
\hline 6 & Septicaemia & $\begin{array}{l}\text { Cutaneous (4) } \\
\text { Haematuria (1) } \\
\text { Haemoptysis (1) }\end{array}$ \\
\hline 6 & $\begin{array}{l}\text { Prematurity: pulmonary } \\
\text { disease }\end{array}$ & Cutaneous (6) \\
\hline 3 & Renal anomalies & $\begin{array}{l}\text { Haematuria and } \\
\text { haemoptysis (2) } \\
\text { Haemoptysis (1) }\end{array}$ \\
\hline 3 & Cirrhosis: atresia of bile duct & Cutaneous (3) \\
\hline 2 & Gastro-duodenal ulcers & $\begin{array}{l}\text { Haematemesis and } \\
\text { melaena (2) }\end{array}$ \\
\hline 2 & Haemolytic disease & Cutaneous (2) \\
\hline 2 & Cold injury & Haemoptysis (2) \\
\hline 2 & $\begin{array}{l}\text { Asphyxia: intracranial haemor- } \\
\text { rhage }\end{array}$ & Haemoptysis (2) \\
\hline 2 & $\begin{array}{l}\text { Asphyxia: suprarenal haemor- } \\
\text { rhage }\end{array}$ & $\begin{array}{l}\text { Haematemesis and } \\
\text { melaena (1) } \\
\text { Cutaneous (1) }\end{array}$ \\
\hline 1 & $\begin{array}{l}\text { *Intracranial haemorrhage: } \\
\text { asphyxia }\end{array}$ & $\begin{array}{l}\text { †Haematemesis and } \\
\text { melaena (1) }\end{array}$ \\
\hline $\begin{array}{l}1 \\
1\end{array}$ & $\begin{array}{l}\text { †Intracranial haemorrhage: } \\
\text { coagulation defect } \\
\text { Suprarenal haemorrhage: } \\
\text { coagulation defect }\end{array}$ & $\begin{array}{l}\text { Cutaneous (1) } \\
\text { Cutaneous (1) }\end{array}$ \\
\hline 1 & Staphylococcal pneumonia & Haemoptysis (1) \\
\hline 1 & Leukaemia & Cutaneous (1) \\
\hline 1 & Thrombocytopenic purpura & $\begin{array}{l}\text { Cutaneous and } \\
\text { haemoptysis (1) }\end{array}$ \\
\hline 1 & Teratoma & Cutaneous (1) \\
\hline
\end{tabular}

* Massive subdural from tentorial tear.

$\uparrow$ Maternal blood.

‡ Intraventricular and subarachnoid. estimated as having a gestation period of less than 38 weeks. The corresponding percentages for the 54 babies with gastro-intestinal bleeding due to swallowed maternal blood were 26 and 28 . Table 8 analyses the onset of haematemesis and/or melaena in relation to the months of the year. The figures suggest that in the winter there may be an increased incidence of these signs when attributable to a coagulation defect, but not when due to swallowed maternal blood.

\section{Deaths}

There were 52 deaths in the total series of 345 cases. Details are summarized in Table 9.

\section{Discussion}

The term 'haemorrhagic disease of the newly born' has lost some of its original clinical significance (Paterson and McCreary, 1956). Apparent bleeding from the gastro-intestinal tract of a newborn infant may be of maternal origin. Primary or intrinsic haemorrhage has to be differentiated from the so-called 'swallowed blood syndrome' (Apt and Downey, 1955; McKay and Smith, 1959; Sanford, 1961). Because of this, babies who vomited or passed blood of maternal origin per rectum have been included in the present study. They numbered 54. Twenty-three were originally diagnosed as suffering from haemorrhagic disease, the majority consisting of infants included in the early stages of the total series of 345 babies. Revision of diagnoses has taken account of subsequent experience gained with babies in whom routine investigations were extended to include estimation of prothrombin time and the differentiation of foetal from maternal blood.

The Swallowed Blood Syndrome. This term applies to the swallowing of maternal blood. It is evident from study of the 54 babies in the present series that maternal blood may be swallowed at any stage during labour and irrespective of whether delivery is spontaneous, instrumental or operative. The findings suggest that there is an especial liability in the presence of antepartum haemorrhage, and that there is always a possibility, after an episiotomy or where the cervix has been lacerated or the perineum torn. A breech presentation is associated with greater risk as the infant's first gasp may take place before delivery of the head. The likelihood of blood being swallowed is further increased when an unrelaxed cervix requires incision, or a short cord has to be severed during delivery. 
The risks of blood being swallowed where there has been antepartum haemorrhage are not necessarily obviated by caesarean section. Difficulty in removing the infant from the uterus may stimulate early gasping movements with resultant swallowing of blood-stained liquor. Staining of the liquor with blood is not limited solely to operative deliveries carried out on account of antepartum haemorrhage; and the possibility of haematemesis or melaena in a newborn infant being evidence of swallowed blood should always be considered whenever delivery has been by caesarean section. The blood will almost certainly be maternal if the placenta has been inadvertently cut at the time of incision of the uterus.

Exceptionally the baby may swallow maternal blood after birth. Two instances occurred in the present series as a result of delay in removing the infant from the labour bed. Both infants were delivered at home in exceptional circumstances; both were born before arrival of the accoucheur, and in the case of one, anxiety concerning the mother diverted attention from the baby.

Haematemesis and/or melaena due to the presence of blood in the mother's milk was an infrequent finding. Usually blood from fissured nipples is present in the form of small clots and gives rise to haematemesis. By way of contrast, the ingestion of milk in which blood is more uniformly distributed is more likely to be followed by melaena than haematemesis. Of three such cases (of which only one is included in this study) seen by the writer, two were subsequently explained by mammary carcinoma, the third remaining undiagnosed.

Haematemesis due to maternal blood swallowed in the course of, or immediately after, delivery developed within two to 36 hours of birth, whereas that due to bleeding from fissured nipples commenced at some time after the fourth day of life.

Visible Haemorrhage. The different situations in which evidence of primary bleeding was encountered in 291 babies agree with those already reported in the literature (Stone, 1945; Wintrobe, 1951; Hughes, 1952; Sanford, 1961). There is general agreement that trauma, infection and congenital anomalies may contribute to haemorrhage.

Routine Procedures. Experience in the present series points to the necessity for being on the alert for bleeding after such routine procedures as circumcision, resuscitative mucus extraction and endotracheal intubation. Resuscitative measures are mentioned by Sanford (1961) as an occasional cause of bleeding, and Wintrobe (1951) describes the bleeding following circumcision as being usually slow and unremitting. Findings in the present study suggest that rapidly exsanguinating haemorrhage of sudden onset after circumcision and from the cord is not altogether uncommon. An incidental finding was that all the examples of exsanguination resulting from ineffective ligation of the cord occurred in hospital practice. A point of practical importance is that haemorrhage from the rectum can be caused by the careless use of a rectal thermometer. One such case not included in this study has been encountered.

Traumatic Cyanosis. Traumatic cyanosis is of special interest if only because of the multitude of overlapping potential contributory factors. There were 35 examples in the present series. Local compression was a feature in seven and foetal distress and/or severe postnatal asphyxia in 11 cases. Four infants showed evidence of severe intracranial irritation, two having convulsions. Of the mothers, no fewer than 12 required special care in the weeks immediately preceding parturition on account of pre-eclampsia (seven), heart disease (two) and active infection (three). Clifford (1939) emphasizes the importance of foetal distress and asphyxia as factors favouring neonatal haemorrhage and Jenny and Gschwend (1958) stress the causal significance of trauma, and capillary permeability and fragility in relation to petechial haemorrhages. In varying degrees anoxia, general circulatory stasis, impaired local venous return and increased capillary permeability were present in the 35 babies under consideration. Nor can the possibility of an associated coagulation defect be excluded in the absence of laboratory studies on these infants. It is not practicable in any general consideration of this subject to apportion particular emphasis to any one possible contributory factor. Nevertheless, in so far as a small number of cases warrants impressions, it appears that factors related to the antenatal health of the mother may be of no less significance than those connected with the mechanical circumstances of delivery.

Infection. Considering infection, haematuria due to secondarily infected hydronephrosis in this series was severe in contrast with Schaffer's experience (1960). Acute oesophagitis is described as a not uncommon cause and congenital syphilis as a rare cause of bleeding by Sanford (1961), but these conditions were not encountered. Other rare causes mentioned by Sanford (1961) are cytomegalic inclusion disease and toxoplasmosis. I have seen one example of each of these conditions and in each 
(neither of which is included in this series) generalized petechiae were present at birth.

Visceral Dysfunction. Findings in this study differ from Schaffer (1960) in that haemolytic disease and haematuria were not features of infants with haemoptysis, and haematuria due to renal thrombosis was not invariably gross. Renal thrombosis can result from damage to the kidney during labour (Jenny and Gschwend, 1958; Schaffer, 1960) and has been seen by the writer, but did not occur in any baby in the present series. The occurrence of petechiae in association with disturbed liver function in newborn infants is well known (Poncher, 1942; Hughes, 1952; Paterson and McCreary, 1956; de Gruchy, 1960). Hepatic dysfunction may explain also the high incidence $(33 \%)$ of bruising noted in macrosomic premature infants with large livers born to mothers with diabetes mellitus (Claye and Craig, 1959). There were two examples of gastroduodenal ulcers, but none of intussusception or volvulus as mentioned by Sanford (1961).

Prothrombin Levels and Prophylactic Vitamin K. A question which inevitably arises is the extent to which this study lends support to prevailing views concerning the significance of the prothrombin level and the efficacy of vitamin $K$ as a form of prophylactic and curative therapy. Poncher (1942) states that spontaneous haemorrhage does not occur and that there is a change in the integrity of the vascular wall in all cases of bleeding. He considers that this change may be due to trauma, venous congestion or anoxia and that the effect of a deficient clotting mechanism is to condition the severity of the haemorrhage. Both Poncher (1942) and Schaffer (1960) are of the opinion that no constant relationship exists between the prothrombin level and a liability to spontaneous bleeding, and Smith (1959) is not satisfied that there is as yet proof that a prolonged prothrombin time is an especial characteristic of prematurity. Nevertheless, Schaffer (1960) comments upon 'the virtual disappearance of haemorrhagic disease with the discovery that vitamin $K$ accelerates the prothrombin time' and Waddell and Guerry (1939) report that not one case of haemorrhagic disease occurred in more than 4,000 newborn babies who were given vitamin $\mathrm{K}$, or whose mothers were given the vitamin antenatally. All 22 premature babies in the group of disturbed coagulation mechanism in the present series were given $2 \mathrm{mg}$. of nikethamide shortly after birth. In addition, four babies born at term in nursing homes, who were transferred to hospital with severe haemorrhage, had, before the onset of bleeding, received vitamin $\mathrm{K}$ in amounts which, today, would be regarded as injudiciously large.

On the assumption that a connexion exists between the prothrombin level and bleeding it has been postulated that the infrequency of bleeding after the fifth day of life can be explained by the bacterial synthesis of prothrombin which follows the oral intake of water or milk feeds (Poncher, 1942; Wintrobe, 1951; de Gruchy, 1960; Sanford, 1961). In the present group of 94 babies with primary gastro-intestinal haemorrhage all those born at term and in whom bleeding commenced after the second day of life had been given oral feeds at least 12 hours before bleeding appeared. Eighteen of the infants were recorded as having been put to the breast for more than 48 hours before the detection of haemorrhage, and six of these infants passed changing milk stools before the onset of visible bleeding. Together these findings justify some doubts as to whether, in fact, either feeds or vitamin $\mathrm{K}$ have a consistently significant preventive value. Antibiotics can interfere with the synthesis of vitamin K (de Gruchy, 1960). They were given to only one or two selected cases and cannot be considered to have confused the general impressions derived from this study.

Vitamin $K$ as a Curative Agent. It is equally difficult to be wholly convinced concerning the curative potentialities of vitamin $\mathrm{K}$. In inclining to this view, I am influenced by admittedly retrospective impressions of my mistaken confidence more than two decades ago in the routine use of intramuscular whole blood. I have records relating to the period 1932 to 1937 of 21 newborn babies to whom whole blood was given intramuscularly on account of haematemesis and/or melaena. There was one death attributable to uncontrollable haemorrhage from multiple gastro-duodenal ulcers. Allowing that in those days differentiation of foetal from maternal blood was not possible, and that the complications of the swallowed blood syndrome were not appreciated, the fact remains that deaths among infants with haemorrhagic disease, as the term was then used, were infrequent. Today the problem remains to know the frequency with which spontaneous arrest of bleeding would take place in the absence of vitamin or other therapy. My personal opinion is that most cases of true haemorrhage attributable to a defective coagulation mechanism would recover spontaneously. Wintrobe (1951) describes the condition as 'self-limited but sometimes fatal'. There can be no questioning the value of whole blood transfusion in dealing with threatening exsanguination. The rapid effect of transfusion 
was a life-saving factor on five occasions in the present study.

The argument can be advanced that evaluation of vitamin $\mathrm{K}$ should take account of its value in preventing complicating, lethal deep or internal haemorrhage. Quick (1942) considers that many cases of intracranial bleeding are due to prothrombin deficiency. It is of significance that among the 52 babies who died in this total series of 345 infants, haemorrhage was the primary cause of death in only five (Table 9). There was laboratory evidence of disturbed coagulation mechanism in only two of these five infants-one infant who had petechial haemorrhage during life and who died as a result of intraventricular and subarachnoid bleeding; and another small premature baby with petechiae before sudden death from suprarenal haemorrhage. By way of contrast there was no prolongation of the prothrombin time in two asphyxiated infants with haemoptysis and intracranial haemorrhage; and in two babies with fatal suprarenal haemorrhage following gastro-intestinal bleeding in one and cutaneous haemorrhage in the other. A disturbed coagulation defect cannot be regarded as a prerequisite of simultaneous bleeding in more than one situation. The present study suggests that such bleeding is most frequently accounted for by circumstances favouring anoxia and that as previously stated (Craig, 1938) defects of coagulation are only very rarely of major importance in the causation of intracranial haemorrhage. Sanford (1948) states he has never seen a case of cerebral haemorrhage with coagulation dysfunction.

External bleeding in an infant is not of itself justification for attributing clinical signs of intracranial irritation to a bleeding tendency. In the present study fatal cerebral haemorrhage followed prolonged postnatal asphyxia in a baby who during life vomited blood which proved to be of maternal origin. Only examination of the blood established the true significance of the bleeding in relation to symptomatology. Moreover, as Wintrobe (1951) emphasizes, signs and symptoms due to intracranial haemorrhage differ little, whether due originally to trauma or to a bleeding tendency.

Again considering a possible relationship between the prothrombin level and apparent spontaneous bleeding, two findings require explanation. If a coagulation defect is the only aetiologically operating factor it is difficult to understand why simultaneous bleedings in multiple sites should not be of commoner occurrence as suggested by Quick (1942). External bleeding in more than one situation occurred in only 24 of the 106 cases of the group concerned in the present study. Equally perplexing is the remarkably high incidence of haemorrhage from the gastro-intestinal tract-an observation recorded in many series (Poncher, 1942; Wintrobe, 1951; Dunham, 1955), but as yet never satisfactorily explained.

\section{Conclusions}

External bleeding, although more frequently met with than internal haemorrhage, is relatively uncommon. It is important to remember that routine resuscitative and nursing measures are among the rare causes of bleeding.

In certain circumstances domiciliary care may favour the occurrence of traumatic bleeding because of unavoidable environmental handicaps in relation to delivery and subsequent care of the infant. This was evident in particular in connexion with superficially situated congenital anomalies. Of equal practical importance was the occurrence of haemoptysis in two small infants who developed cold injury some days after delivery at home. It is justifiable to draw attention to the fact that no fewer than 36 of the 94 babies with intrinsic alimentary bleeding were born in their own homes. If a relation exists between seasonal or environmental temperature and the occurrence of primary gastrointestinal haemorrhage, the large number of domiciliary cases may reflect the effect of home conditions in a way analogous to that found in cold injury. The findings in the present series provide evidence also of the risks attendant upon birth of a baby in the absence of a professional attendant, circumstances virtually peculiar to domiciliary practice.

It should not be assumed, however, that inhalation of maternal blood after delivery occurs only in domiciliary practice. Albeit extremely rarely, it does occur in nursing homes and in hospital labour wards.

Moreover, another finding deserving mention is that the examples of exsanguination as a result of bleeding from the cord occurred in hospital. While this allows of no dogmatic conclusions it suggests at least that procedures undertaken by medical students and pupil midwives should be subject to the most careful supervision. On the other hand injudicious attempts to accelerate separation of the cord were encountered only in babies being delivered at home.

Hypothermia and sustained bradycardia with a sluggish circulation, separately or in combination, may increase the likelihood of bleeding in the presence of an additional contributory factor such as trauma or infection. The rarity with which external bleeding gives rise to an emergency situation is added reason for those responsible for the care of the newborn being trebly on the alert for the 
exceptional situation. This applies particularly to routine periodical examination of the cord after delivery and the penis after circumcision. Premature babies should be kept under constant observation. They are unable to stand severe blood loss and the general systemic effects of severe haemorrhage are liable to be masked by frailty. Visible evidence of gastro-intestinal bleeding may afford no indication of the severity of the haemorrhage. Laboratory tests and consideration of the obstetrical history are essential in determining the source of blood in cases of haematemesis and melaena.

External bleeding is rarely fatal, but a confident prognosis must be based on the exclusion of coexistent deep internal haemorrhage. In the absence of explanatory trauma or infection, the aetiology of external bleeding often remains uncertain. As with so many other conditions in the newborn, bleeding may be the result of an aggravation of normal postnatal variations in the blood constituents. Just as the therapeutic use of vitamin $\mathrm{K}$ must be judicious so must the interpretation of the results of treatment. The many factors involved in the control of bleeding are only now being unravelled and current opinions concerning the value of vitamin $\mathrm{K}$ may have to be reviewed.

\section{Summary}

A clinical study is presented of 345 newborn babies with external signs of bleeding, real or apparent.

Bleeding is discussed in terms of haematemesis, melaena, haematuria, haemoptysis, epistaxis, petechiae, ecchymoses, contusions or as haemorrhage following circumcision or from the cord.

The aetiological significance of trauma, infection, congenital anomalies and defective coagulation mechanism of the blood is considered.

The circumstances in which haematemesis and melaena may be due to swallowed maternal blood are reviewed.

It is considered that maternal factors may influence the occurrence of traumatic cyanosis.

Observations lend support to the view that the incidence of intrinsic gastro-intestinal haemorrhage is subject to seasonal variations, but do not confirm that the condition is found most commonly in premature babies.

Reasons are advanced for questioning the value of vitamin $K$ therapy in the prophylactic and curative treatment of primary intrinsic gastrointestinal haemorrhage of the newborn.

Attention is drawn to circumstances of hospital and domiciliary practice with a bearing on bleeding in the newborn.

The study would not have been possible without assistance from many colleagues including senior obstetricians and family doctors. I am especially indebted to Dr. William Goldie for generously given invaluable advice and criticism; to Dr. John Thomson, Dr. M. Coles and Miss E. M. Bond for help in analysing clinical records; to Sister M. Pattullo, Sister R. White and Sister E. Oliver for their co-operation in the nurseries; and to $\mathrm{Mr}$. $\mathrm{R}$. Martindale for laboratory examinations and reports.

\section{REFERENCES}

Apt, L. and Downey, W. S. (1955). Melena neonatorum-the swallowed blood syndrome. J. Pediat., 47, 6.

Claye, A. M. and Craig, W. S. (1959). Pregnancy comolicated by diabetes mellitus. A study in combined obstetric and paediatric management. Arch. Dis. Childh., 34, 312.

Clifford, S. H. (1939). Haemorrhagic disease of the newborn. J. Pediat., 14, 333 .

Craig, W. S. (1938). Intracranial haemorrhage in the new-born: A study of diagnosis and differential diagnosis based upon pathological and clinical findings in 126 cases. Arch. Dis. Childh., 13, 89.

de Gruchy, G. C. (1960). Clinical Haematology. Blackwell, Oxford. Dunham, E. C. (1955). Premature Infants, 2nd ed. Cassell,

London. Hill, New York.

Jenny, J. and Gschwend, E. (1958). Uber die Blutungskrankheiten beim Neugeborenen. Geburts. u. Frauenheilk., 18, 36.

McKay, R. J. and Smith, C. A. (1959). Textbook of Pediatrics, 7 th ed., ed. W. E. Nelson. Saunders, Philadelphia and London.

Paterson, D. H. and McCreary, J. F. (1956). Pediatrics. Lippincott, Philadelphia.

Poncher, H. G. (1942). The rôle of vitamin $\mathrm{K}$ in hemorrhage in the newborn period. In Advances in Pediatrics, ed. A. G. De Sanctis, Vol. 1, p. 151. Interscience, New York.

Quick, A. J. (1942). The Hemorrhagic Diseases. Charles C. Thomas, Springfield, Illinois.

Sanford, H. N. (1948). The Child in Health and Disease, ed. C. G. Grulee and R. C. Eley. Williams and Wilkins, Baltimore.

- (1961). Brennemann's Practice of Pediatrics, ed. I. McQuarrie and V C. Kelley, Vol. III, Ch. XV. Prior, Hughstown, Maryland.

Schaffer, A. J. (1960). Diseases of the Newborn. Saunders, London. Schaffer, A. J. (1960). Diseases of the Newborn. Saunders, London.
Smith, C. A. (1959). The Physiology of the Newborn Infant, 3rd ed. Blackwell, Oxford.

Stone, E. L.'(1945). The New-Born Infant, 3rd ed. Kimpton, London.

Waddell, W. W. and Guerry, Du P. (1939). Effect of vitamin K on clotting time of prothrombin and blood, with special reference to unnatural bleeding of newly born. J. Amer. med. Ass., 112, 2259 .

Wintrobe, M. W. (1951). Clinical Hematology, 3rd ed. Kimpton, London. 